\title{
Overweight and obesity: a brief challenge on prevalence, complications and physical activity among men and women
}

\begin{abstract}
Obesity is a major problem for public health due to weight gain from imbalance between energy intake and energy expenditure. According to published data by World Health Organization (WHO), obesity was increased rapidly from outset of last decades of 1900. Prevalence of obesity is accepted as a socioeconomic challenge in present decade. Based on this topic, in particular since 1980 decade, if this trend cannot be reversed or at least restrained, high levels of obesity will naturally lead to increases in the prevalence of chronic diseases, with enormous economic and personal costs. Epidemiological reports show, in 2008, approximately $35 \%$ of adults were overweight (body mass index $[\mathrm{BMI}] \geq 25-29.9 \mathrm{~kg} / \mathrm{m} 2$ ) ( $34 \%$ men and $35 \%$ of women). The worldwide obesity prevalence has increased meaningfully between 1980 and 2008 . In $2008,10 \%$ of men and $14 \%$ of women in the world were obese (BMI $\geq 30 \mathrm{~kg} / \mathrm{m} 2)$, compared with $5 \%$ for men and $8 \%$ for women in 1980. An estimated 205 million men and 297million women over the age of 20 were obese a total of more than half a billion adults worldwide. Since physical activity rates over the past three decades are essentially unchanged or lower, it would seem that increased body mass has limited the weight gain due to increased energy output. As a result, obesity prevention has become an international priority. Changes in life habits and patterns, such as dietary behaviors, advancing in technology, relief, sedentary life, and decrease of lifestyle physical activities, results in an increase of obesity and weight gain among men and women. Obesity is related to increased morbidity and mortality rates due to coronary heart disease (CHD), osteoarthritis, infectious disease and cancers. Excessive body weight, in addition, increases the risk of hypertension, unhealthy lipid profile, menopauses, gallbladder disease, diabetes, some cancers, psychosocial experiences, and many other causes of chronic morbidity. Obesity, in addition, involves major expenditure and therefore represents a socioeconomic health problem of the highest magnitude. It is clear that obesity as worldwide problem results in considerable morbidities and decrease individuals abilities for keep their good health for live. In this review we try that augment this history argument, epidemically and represent the relation between physical activities and weight control among men and women.
\end{abstract}

Keywords: obesity prevalence, fatness related-disease, physical fitness, weight control
Volume 7 Issue I - 2018

\author{
Javad Mehrabani, Zeynab Khazraei Ganjifar \\ Department of Exercise Physiology, Faculty of Physical \\ Education and Sport Sciences, University of Guilan, Iran
}

Correspondence: Javad Mehrabani, Department of Exercise Physiology, Faculty of Physical Education and Sport Sciences, University of Guilan, P.O Box 1438, Rasht, Iran, Tel/Fax +980I3I-6690675,Email mehrabanij@gmail.com

Received: August 21, 2017| Published: January 17, 2018

\section{Obesity defination and measurment}

To most non-professionals, obesity means very fat and overweight means either less fat. Whereas overweight implied to excess body weight compared to set standards, obesity refers specifically to having an abnormally high proportion of fat. ${ }^{1}$ To health professionals and researchers, however, both these terms have definitions that specify the degree of excess fat. ${ }^{2}$ Body fat exists in storage and essential forms. Essential fat found in all organs involving the central nervous system or intestines that is necessary for body normal functions. Storage fat as an efficient energy fuel is accumulated in the adipose tissue, specially under the skin and that is affected by diet or exercise, whereas the amount of essential fat remains constant. ${ }^{3}$ World health organization, in addition, produced a definition of obesity based on Body Mass Index (BMI), as a criterion taking into particular consideration the correlation between this index and mortality and disability. ${ }^{4}$ Indeed, body fatness assessed by BMI that is calculated by easily and quickly dividing an individual's weight measured in kilograms by their height in meters squared $\left(\mathrm{kg} / \mathrm{m}^{2} ;\right.$ e.g., a men weighing $80 \mathrm{~kg}$ and measuring $\left.1.7 \mathrm{~m}, \mathrm{BMI}=80 /(1.7 \times 1.7)=27.7 \mathrm{~kg} / \mathrm{m}^{2}\right)$. This index is independent of gender and age. ${ }^{2}$ Table 1 shows accepted scale of BMI for degrees of overweight and obesity by WHO. ${ }^{5,6}$ Defined objectively as a BMI of 30 or more, obesity is related with markedly increased health risks. Although, a BMI of $25 \mathrm{~kg} / \mathrm{m}^{2}$ is the commonly accepted threshold for recognizing bedridden identifying a patient at higher risk for obesityrelated illnesses. ${ }^{7}$

Individuals who have a BMI of $\geq$ have a $50-100 \%$ increased death hazard from all causes compared with individuals who have BMI 20$25 \mathrm{~kg} / \mathrm{m}^{2} .{ }^{8}$ Morbid obesity is defined by a BMI $\geq 40.0 \mathrm{~kg} / \mathrm{m}^{2}$. Body mass index calculation as a test for reorganization of overweight and obesity, although, is not a perfect measure, but it is the industry standard, as its formula makes it certainly accurate enough to determine presence of increased health hazard. ${ }^{9,10}$ It, indeed, has replaced percentage ideal body weight as a criterion for assessing obesity for several reasons. ${ }^{7}$ It is not proper index in individuals with a great muscle mass (such as bodybuilders) and falsely low in those that have lost muscle mass, such as the elderly. ${ }^{11}$ The main assumption of BMI guidelines is that body mass, adjusted for stature squared, is closely associated with 
body fatness and consequent morbidity and mortality. ${ }^{12,13}$ On base of BMI data, men have more BMI when compared with women, generally. However, more men are overweight than women, but in almost more women than men are obese through the world. ${ }^{14}$ Same to BMI, Waist Circumference (WC) is a useful predictor, commonly, for Coronary Heart Disease (CHD) risks and undesirable profile of blood fats (Table 1). It is reported that there is a clear relation between the accumulation intra-abdominal fat and WC and increased hazards. ${ }^{5}$ On this base, WHO suggested WC measures for predict of hypertension and lipid disorders, particularly low high density lipoprotein (HDL) cholesterol, added to crudely predicted whether people were overweight or obese. ${ }^{6}$ Waist circumference, indeed, is an independent hazard for raised risk of backwash from obesity that increased. It can indeed be a marker for increased risk even in persons of normal weight. ${ }^{7}$

Table I Classification of obesity and comorbidity risks

\begin{tabular}{|c|c|c|}
\hline Classification & BMI $\left(\mathrm{kg} / \mathrm{m}^{2}\right)$ & Comorbidity risks \\
\hline \multirow[b]{2}{*}{ Underweight } & \multirow[b]{2}{*}{$<18.5$} & Low (But risk of other \\
\hline & & $\begin{array}{l}\text { Clinical problems } \\
\text { increased) }\end{array}$ \\
\hline Normal range & $18.5-24.9$ & Average \\
\hline Overweight (Pre-obese) & $25.0-29.9$ & Increased \\
\hline Obesity & \multicolumn{2}{|l|}{$\geq 30.0$} \\
\hline Obese class 1 & $30.0-34.9$ & Moderate \\
\hline Obese class 2 & $35.0-39.9$ & Severe \\
\hline Obese class 3 & $\geq 40.0$ & Very severe \\
\hline \multirow{2}{*}{ Comorbidity risks } & \multicolumn{2}{|c|}{ Waist Circumference $(\mathrm{cm})$} \\
\hline & Women & Men \\
\hline Above action level 1 & $\geq 80$ & $\geq 94$ \\
\hline Above action level 2 & $\geq 88$ & $\geq 102$ \\
\hline Data from reference: ${ }^{6}$ & & \\
\hline
\end{tabular}

\section{Obesity and diseases}

Overweight and obesity are considered the third most important hazard attributable to burden of disease. There was approximately 350 million obese people $(\mathrm{BMI} \geq 30.0)$ and over 1billion overweight people (BMI $\geq 25)$ in the world in the beginning of this century. Over all more than 2.5 million deaths are, in addition, attributed to overweight/ obesity worldwide. ${ }^{6}$ Since that time, the population of obese people has risen and is still rising in advanced countries. According to "Obesity Update 2017 Report" published by Organization for Economic Cooperation and Development (OECD), more than one in two adults and nearly one in six children are overweight or obese in 2015, across OECD countries, $19.5 \%$ of the adult population was obese. This rate ranges from less than $6 \%$ in Korea and Japan to more than $30 \%$ in Hungary, New Zealand, Mexico and the United States (US). More than one in four adults is obese in Australia, Canada, Chile, South Africa and the United Kingdom (UK). Overweight and obesity rates have grown rapidly in England, Mexico and the US since the 1990s, while the increase has been slower in the other seven OECD countries.

Over the past decade, the prevalence rate of overweight and obesity has increased in Canada, France, Mexico, Switzerland and the US. ${ }^{15}$ Different studies have been showed an association between obesity and mortality factors such as diabetes, hypertension, $\mathrm{CHD}$, and some cancers. Namely it is estimated that for every $1 \mathrm{~kg}$ increase in weight, the prevalence of diabetes rises by $9 \% .{ }^{16-18}$ It has indeed been known that obesity is a marked determinant of high levels total cholesterol and triglycerides, and low levels of HDL cholesterol. ${ }^{10} \mathrm{BMI}, \mathrm{WC}$ and waist-to-hip ratio (WHR) have also been reported that as strong risk factors for colon cancer. ${ }^{19}$ WHR is a useful method for assessment of central obesity. ${ }^{20}$ It have been reported that obesity may decrease the ability of insulin to widen blood vessels. It indeed changes function of kidney and sodium balance that lead to hypertension. ${ }^{6}$ Furthermore, obesity has more psychological and social effects, involving low self esteem and discrimination. ${ }^{11}$ In general, obesity increases the risk of many diseases and health conditions that exhibited in Tables 2, Table 3 . With increase of BMI from $23 \mathrm{~kg} / \mathrm{m}^{2}$, compared with the lowest hazard category, risk of mortality rises progressively. Death hazards, indeed, increases with rising of BMI from $25 \mathrm{~kg} / \mathrm{m}^{2}$, through 1,2 , and 3 obesity classes, ${ }^{7,21}$ defined in Table 1 . It is evident that sedentary lifestyle is an independent risk factor for heart related deaths..$^{22}$ According to estimates, more than half of disease is lifestyle related. Indeed, the scientific literature shows that adverse modifiable health risks such as physical inactivity and obesity are related to morbidities. ${ }^{23}$ One of the sedentary life related hazards is accumulation of fat in trunk that increased WC and WHR rates. ${ }^{24}$ This condition is related with hypertrophic obesity. Enlarged fat cells is symptoms of hypertrophic obesity (often begins in adulthood), that result in production of proteins and metabolites such as lipoprotein lipase (LPL), which communion to hydrolysis of the triglycerides of very low density lipoproteins (VLDL) and chylomicrons, and cytokines (tumor necrosis factor- $\alpha$, and interleukin-6), leptin (a hormone involved in animal models of obesity), as well as angiotensinogen. ${ }^{1,2}$ The hypertrophic fatness is correlates to obesity metabolic disorders such as damaged glucose tolerance and adverse lipid profile. ${ }^{7}$ Whereas, in patients with a BMI $\geq 40 \mathrm{~kg} / \mathrm{m}^{2}$ occurred hypercellular obesity (often begins in childhood) that is a lower hazard type of illnesses. ${ }^{22}$ It seems aging is an effectiveness variable in identification of hypertrophic obesity that occurred in adults. Therefore, age is important factor in investigation of side effects of hypertrophic obesity. Of note, individuals who have a BMI equal or more than $30 \mathrm{~kg} / \mathrm{m}^{2}$ must lessen their weight irrespective of WC rate or its hazards. Indeed, loss weight should be lionized for normal weight women who have $\mathrm{WC} \geq 88 \mathrm{~cm}$ or men who have $\geq 102$ $\mathrm{cm}$, as well as two or more of the tabled hazards. ${ }^{7}$

Table 2 Health complications of obesity
Dyslipidemia (for example, high total cholesterol or high levels of triglycerides)

$\begin{array}{ll}\text { Fatty infiltration of liver } & \begin{array}{l}\text { Gynecological problems } \\ \text { (abnormal menses, infertility) }\end{array} \\ \text { Hypothyroidism } & \text { Mental and nervous disorders, } \\ \text { Immune disorders } & \text { Seizure disorders } \\ \text { Digestive diseases } & \text { Neoplasias } \\ \text { Stroke } & \text { Insulin resistance syndrome }\end{array}$

Stroke Insulin resistance syndrome

Liver disease

* Data from references: ${ }^{6,7,25,26}$

Sleep apnea and respiratory problems

\section{Gynecological problems} (n) infertility) Mental and nervous disorders,

(1) 
Table 3 Relation between obesity and many diseases

\begin{tabular}{ll}
\hline Type-2 diabetes (6I\%) & Coronary Heart Disease (I7\%) \\
Endometrial Cancer (34\%) & Hypertension (17\%) \\
Gallbladder Disease (30\%) & Colon Cancer (I I\%) \\
Osteoarthritis (24\%) & Breast Cancer (I I\%) \\
*Data from reference: &
\end{tabular}

\section{Physical activity and weight management}

One of the reactions of health associations to rise of obesity epidemic and the necessity for physicians to diagnose and treat obesity as a worldwide problem is to be active physically. Modification concentrated on increasing physical activity must involve improvement of physical activities and restriction of sedentary hours. It seems sedentary lifestyle as a negative social paradigm lead to prevalence of obesity and side effects that its extreme will be an unhealthy and bedridden society. ${ }^{24-26}$ For this aim should promote people attitude about physical activity and exercise benefits. ${ }^{27}$ It seems for improve of health and disease prevention, physical fitness is more important than a reduction in body fat. Many scientists have expressed a new perception on relation between obesity and physical activity. They have believed that obesity as result of "fat" accumulation is versus "fit" as output of physical activity. They believe that fitness level is premier to health than body fatness, and fit obese individuals are at less risk than unfit normal weight individuals. ${ }^{18}$ For example, in a crosssectional study, we investigate the prevalence of obesity, overweight and lifestyle physical activities in Public Transport Drivers in Tehran. We observed a significant negative relationship between body mass index and with spending work and leisure time physical activities and being careful about what and how much is eaten. ${ }^{23}$

Whereas, some researchers believe that obesity has multiple possible determinants, ${ }^{28}$ physical activity level and diet are majored variables. Individuals are more likely to do physical activity if they have a positive attitude towards its benefits. ${ }^{3}$ A lot of studies have been showed overt inverse relation between perform physical activity, obesity and its side effects. ${ }^{4,29-31}$ For this aim, have been developed and published guidelines by many institutes and organizations such as the National Institutes of Health (NIH), ${ }^{32}$ the North American Association for the Study of Obesity (NAASO), American College of Sports Medicine (ACSM), and WHO. In that guidelines, there is recommendations on optimum levels of physical activities involves intensity, duration, frequency, and type of them. It seems follow a suitable exercise program can lead to decrease of fatness and treatment of obesity and increase of fitness. ${ }^{33,34}$ Weight loss in overweight and obese individuals can reduce the risk of heart disease. ${ }^{14} \mathrm{~A}$ lot of studies show that weight loss, even if $5-10 \%$, meaningfully improves lipoproteins, high blood pressure, insulin resistance, risk for osteoarthritis, cancers, and other hazards for chronic illnesses. ${ }^{35,36}$ Diet is of paramount importance in the management of weight and obesity depended complications. It is accepted that a composition of dietary changes (diet with less calories and fat) and increased regular physical activities is the proficiency method to promote weight loss and to maintain the weight loss..$^{14,28,37}$ Diet and regular physical activity as behavior habits are associated with strong beliefs that influence one's own health, too. ${ }^{38}$ Above sentence show a relation between daily behaviors and psychological outcomes.

Indeed, choice of suitable diet with doing regular physical activities on recommended guideline lead to qualified life. This question "How much physical activity is sufficient to avoid weight gain" always set as a major challenge among scientists and researchers. A study on women who had successfully lost their weight, show obese individuals needs 60-90min physical activity with moderate intensity or lesser amounts of vigorous exercise ${ }^{39,40}$ For example, the women who did more than 2hours vigorous physical activity per week show an inverse relation with increased weight and obesity. ${ }^{10}$ It seems there are not acceptable evidences on requirement physical activity for prevent of weight gain. It is not known. However, on basis of different recommendations 4560 min activity per day with moderate intensity is needed to avoid excess weight gain. ${ }^{2,39,40}$ Perhaps, most recommended successful treatment strategy involves an interaction of physical activity, diet therapy, and behaviors improvement therapy that set by National Heart, Lung and Blood Institute. ${ }^{33}$ Same to inactivity, age is strongly associated with obesity. ${ }^{41}$ It seems with aging reduce physical activity level that lead to an imbalance in input and expenditure of energy. Indeed, disuse of energy intake and decrease of energy expenditure results in fat accumulation in subcutaneous area and obesity occurred gradually.

\section{World wide epidemic}

It has been show that prevalence of obesity and overweight is high in countries that have an established economy, ${ }^{42,43}$ as well as developing countries., ${ }^{4,26,42}$ Added with economy conditions, there is a clear inverse relation in most countries between the prevalence of obesity and different society variables included culture, ecology, and level of education. ${ }^{23,39,42-44}$ According to new WHO analyses of global burdens in the different subregions of the world, there is a remarkable variation in the prevalence of both overweight and obesity. Obesity is clearly more prevalent in women than men worldwide. ${ }^{5,45}$ Prevalence of overweight and obesity, indeed, is higher in industrial countries than developing and undeveloped countries (Figure 1). Besides, it is in addition a major health concern in developing nations and other regions of the world. ${ }^{38,42}$ This increased prevalence maybe reflects a change in lifestyle patterns influenced by an overabundance of food choices and fatty foods, industrialization, technology, ${ }_{4}$ and convenience, with decrease opportunities and motivation for regular physical activity. Prevalence of obesity varies in different countries in worldwide. ${ }^{42,44,46}$

The causes of this epidemic are influenced by many social, cultural, and economic variables that determine the quantity and quality of energy intake and energy expenditure ${ }^{47-49}$ such as food patterns and physical activities. This value for Europe as well as other developed countries is estimated to average $15-20 \%$ of the population. In 1995, 10-20\% of European men and $15-25 \%$ of women were obese, ${ }^{39}$ having increased $10-40 \%$ in the last decade. ${ }^{11}$ Recently a comprehensive and detailed report on the obesity epidemiology show that, more than $50 \%$ of the 693 million obese persons in the world live in 10 countries including USA, China, India, Russia, Brazil, Mexico, Egypt, Pakistan, Indonesia, and Germany. ${ }^{50}$ In Europe, it has been estimated $22 \%$ of children, $26 \%$ of men and $31 \%$ of women to be obese. In the UK (a developed European country) the increase of obesity prevalence between 1993 and 2003 was $43 \%$ for women and $74 \%$ for men. ${ }^{39}$ Whereas, paradoxically, between 1997 and 2003 number of individuals achieved a physical activity for $>30 \mathrm{~min}$ moderate intensity activity on a minimum of 5 days per week were increased. ${ }^{39,40}$ In Ireland (neighbor of UK) prevalence of obesity was $18 \%$ and overweight $39 \% .{ }^{37}$ The Europe PMC Funders Group 
recently released a report that showed an increase in the prevalence of obesity over the past years in both developed and developing countries. Globally, the proportion of adults with a BMI of 25 or greater increased from $28.8 \%$ in 1980 to $36.9 \%$ in 2013 for men and from $29.8 \%$ to $38.0 \%$ for women. ${ }^{50}$ Prevalence of obesity and its side effects such as type 2 diabetes have also been increasing in the AsiaPacific region of the world..$^{3}$

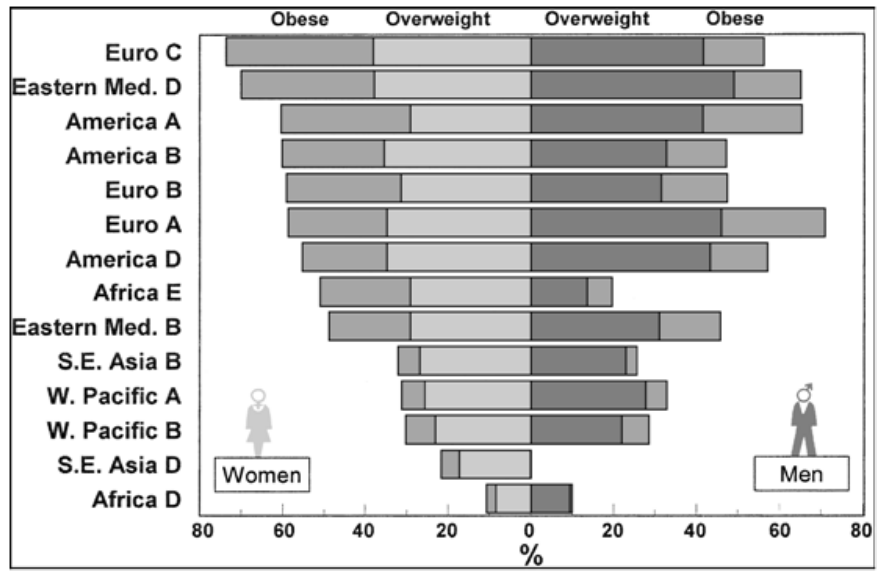

Figure I Worldwide initial estimates on prevalence of overweight and obesity in 45- to 59-year-old. Note that 191 countries are divided in the any subregion, which have been constructed on the basis of the observed infant mortality rates and life expectancies of the different countries. From any subregion, the three countries with the biggest populations are defined below:

(Afr D: Nigeria, Algeria, and Ghana); (Afr E: Ethiopia, Congo, and South Africa); (Amr A: US, Canada, and Cuba); (Amr B: Brazil, Mexico, and Colombia); (Amr D: Peru, Ecuador, and Guatemala); (Eastern Med B: Iran, United Arab Emirates, and Saudi Arabia); (Eastern Med D: Pakistan, Egypt, and Sudan); (Eur A: Germany, France, and UK); (Eur B: Turkey, Poland, and Uzbekistan); (Eur C: Russian Federation, Ukraine, and Kazakhstan); (Sothern Asia B: Indonesia, Thailand, and Sri Lanka); (Sothern Asia D: India, Bangladesh, and Myanmar); (Western Pacific A: Japan, Australia, and Singapore); and (Western Pacific B: China,Vietnam, and Philippines). ${ }^{5}$

One of methods for assessment of obesity is BMI values that currently used underestimates risk in Asians. Rates of absolute BMI values in Asia-Pacific individuals are more intense when compared to their European descendant counterparts. ${ }^{3,51}$ Prevalence of obesity has doubled among Japanese men and young women in the last two decades. ${ }^{11}$ Island nations in the Pacific and the Caribbean, and countries in the Middle-East and Central America, have already reached particularly high rates of overweight and obesity. ${ }^{50}$ In Iran, as well as other developing countries, prevalence of overweight and obesity is ongoing. Based on data from first survey of the noncommunicable disease risk factor surveillance system of Iran, 19.2\% of Iranian women and $9.1 \%$ of men aged 15-64years are obese. A $48.5 \%$ of women and $37 \%$ of men, indeed, have BMI $\geq 25.0 \mathrm{~kg} / \mathrm{m}^{2}$. In general, $42.8 \%$ of Iranian adults aged 15-64years was overweight and $14.2 \%$ are obese in $2005 .{ }^{51}$ In a cross-sectional study, we investigate the prevalence of obesity, overweight and lifestyle physical activities in Public Transport Drivers in Tehran. Rate of obesity, overweight and both of them were $26.6 \%, 40.6 \%$, and $67.2 \%$, respectively. Furthermore, a significant relationship was observed between body mass index and much food consumption habits, for example using high-fat foods, candies, snacks, desserts. ${ }^{23}$ Indeed, a global systemic review analysis (2015) show the $21.6 \%$ overweight and $5.9 \%$ obesity vs. $26.2 \%$ and $7.2 \%$ for Iranian male and female under 20 years old age, respectively. In addition, above 20 years old age, the statistics show that a $49.4 \%$ overweight and $13.6 \%$ obesity vs. $63.3 \%$ and $29.3 \%$, respectively. ${ }^{51}$ In Africa continent, higher rates have been reported in black men and women $10 \%$ and $44 \%$, respectively. It is reported, whereas, that a low rates of obesity prevalence (0.6-3.6\%) in blacks from East and West Africa. ${ }^{52}$ In Ghana (a country in West Africa continent) the prevalence of overweight was $23.4 \%$ and obesity was $14.1 \%$. The prevalence of overweight and obesity were higher in females than males ( 27.1 vs. $17.5 \%$ and 20.2 vs. $4.6 \%$ ), respectively. ${ }^{53}$ This evidence is confirmed by the Non-communicable Disease Risk Factor Collaboration (NCD-RisC) network. This worldwide network has showed that between 1975 and 2014, the BMI of women and men has increased. ${ }^{54}$ They reported that global age-standardized mean BMI increased from $21.7 \mathrm{~kg} / \mathrm{m}^{2}$ in 1975 to $24 \cdot 2 \mathrm{~kg} / \mathrm{m}^{2}$ in 2014 in men, and from $22 \cdot 1 \mathrm{~kg} / \mathrm{m}^{2}$ in 1975 to $24 \cdot 4 \mathrm{~kg} / \mathrm{m}^{2}$ in 2014 in women.

In the US, prevalence of obesity -BMI- continues to be a health problem for adults, children and adolescents. In this country the prevalence of obesity raised by $74 \%$ from 1991 to $2001 .^{39}$ It is reported that from recent National Health and Nutrition Examination Survey (NHANES) survey ${ }^{39}$ among adult men the prevalence of obesity was $31.1 \%$ in $2003-2004$, and $33.3 \%$ in $2005-2006$. This rate in 2003-2004 for women was 33.2\%, and in 2005-2006 was $35.3 \%$. It is clear that intake of fast foods and nutrition with high fat are effective factors for increased obesity prevalence in the US. ${ }^{55}$ Notable, in a study on different strains have conducted by Gallagher (2000), BMI rate was highest in African American women and lowest in Asian women and men. ${ }^{12}$ More surveys on obesity epidemic show that transcend of obesity among women than men. ${ }^{5}$ Based on above sentences, it is clear that obesity is increasing in different countries, rapidly. OECD projections show a steady increase in obesity rates until at least 2030. Obesity levels are expected to be particularly high in the US, Mexico and England, where $47 \%, 39 \%$ and 35\% of the population respectively are projected to be obese in $2030 . .^{56}$ Therefore, treatment of obesity and avoid from excess weight gain is necessary for decrease of obesity related diseases. Naturally, for this intention modification of many lifestyle behaviors such as food patterns and level of physical activities have priority. It is vivid to overtake this aim need to a global standpoint.

\section{Conclusion}

The prevalence of obesity increased rapidly in last decades worldwide. For this modification, many variables such as change in lifestyle induced westernize, industrialization, relief, diets and decrease of physical activity are considerable. Thus, for maintenance of optimum weight it is necessary that reform nutrition behaviors and increase level physical activities. In addition, it is consideration to both fatness and fitness in interventions is very important.

\section{Acknowledgements}

None.

\section{Conflict of interest}

The author declares no conflict of interest.

\section{References}

1. Bray GA, Ryan DH. Clinical evaluation of the overweight patient. Endocrine. 2000;13(2):167-186. 
2. Ruhl CE, Everhart JE. Leptin concentrations in the United States: relations with demographic and anthropometric measures. Am J Clin Nutr. 2001;74(3):295-301.

3. Wilborn C, Beckham J, Campbell B, et al. Obesity: Prevalence, theories, medical consequences, management, and research directions. $J$ Int Soc Sports Nutr. 2005;2:4-31.

4. Process for a global strategy on diet, physical activity and health Geneva. Swizterland: World Health Organization; 2003.

5. James PT, Leach R, Kalamara E, et al. The worldwide obesity epidemic Obes Res. 2001;9:228S-233.

6. Obesity: preventing and managing the global epidemic. WHO obesity technical report series 894 . Switzerland; 2000.

7. Aronne LJ. Classification of obesity and assessment of obesity-related health risks. Obes Res. 2002;10:105S-115.

8. Finkelstein EA, Fiebelkorn IC, Wang G. State-level estimates of annua medical expenditures attributable to obesity. Obes Res. 2004;12(1):18-24.

9. Center for Disease Control and Prevention (CDC).

10. Martínez-Ros MT, Tormo MJ, Navarro C, et al. Extremely high prevalence of overweight and obesity in Murcia, a Mediterranean region in south-east Spain. Int J Obes Relat Metab Disord. 2001;25(9):1372-1380.

11. Jain A. What works for obesity? USA: BMJ Publishing Group Limited; 2004.

12. Gallagher D, Heymsfield SB, Heo M, et al. Healthy percentage body fat ranges: an approach for developing guidelines based on body mass index. Am J Clin Nutr. 2000;72(3):694-701.

13. Willett WC, Hu FB, Thun M. Overweight, obesity, and all-cause mortality. JAMA. 2013;309(16):1681-1682.

14. Beer-Borst S, Morabia A, Hercberg S, et al. Obesity and other health determinants across Europe: The EURALIM Project. $J$ Epidemiol Community Health. 2000;54(6):424-430.

15. https://www.oecd.org/els/health-systems/Obesity-Update-2017.pdf

16. Elizondo-Armendariz JJ, Grima G, Ontoso A. Prevalence of physical activity and its relationship to sociodemographic variables and lifestyles in the age 18-65 population of Pamplona, Spain. Rev Esp Salud Publica. 2005;79(5):559-567.

17. Hardman AE, Stensel DJ. Physical activity and health: the evidence explained. UK: Routledge; 2004.

18. Sullivan PW, Morrato EH, Ghushchyan V, et al. Obesity, inactivity, and the prevalence of diabetes and diabetes-related cardiovascular comorbidities in the U.S, 2000-2002. Diabetes Care. 2005;28(7):1599-1603.

19. Giovannucci E, Ascherio A, Rimm EB, et al. Physical activity, obesity, and risk for colon cancer and adenoma in men. Ann Intern Med. 1995;122(5):327-334.

20. Azadbakht L, Mirmiran P, Shiva N, et al. General obesity and central adiposity in representative sample of Tehranian adults: prevalence and determinants. Int J Vitam Nutr Res. 2005;75(4):297-304.

21. Flegal KM, Kit BK, Orpana H, et al. Association of all-cause mortality with overweight and obesity using standard body mass index categories: A systematic review and meta-analysis. JAMA. 2013;309(1):71-82.

22. Bray GA. Reciprocal relation of food intake and sympathetic activity: experimental observations and clinical implications. Int $J$ Obes. 2000;24:S7-S8.
23. Mehrabani J, Damirchi A, Ganjifar KZ. Obesity and associated risk factors among adult males: prevalence investigation in crosssectional study. Medicina Sportiva. 2017;13(2):2888-2896.

24. Ursla GK, Morbia A, Schantz Y, et al. Sedentarism affects body fat mass index and fat-free mass index in adult aged 18 to 98 years. Nutrition. 2004;20(3):255-260.

25. https://www.niddk.nih.gov/health-information/weight-management/ health-risks-overweight

26. U.S. Department of Health and Human Services. Healthy People. 2nd ed. With Understanding and Improving Health and Objectives for Improving Health. USA: U.S. Government Printing Office; 2010.

27. Swinburn B, Egger G. Prevention strategies against weight gain and obesity. Obes Rev. 2002;3(4):289-301.

28. Howard BV, Bogardus C, Ravussin E, et al. Studies of the etiology of obesity in Pima Indians. Am J Clin Nutr. 1991;53(6 Suppl):1577S-1585.

29. Adami GF, Cordera R. Association of body mass index, physical activity and eating pattern in adult men. Nutr Res. 2003;23(5):579-583.

30. Erem C, Yildiz R, Kavgaci H, et al. Prevalence of diabetes, obesity and hypertension in a Turkish population (Trabzon city). Diabetes Res Clin Prac. 2001;54(3):203-208.

31. Luke A, Cooper RS. Physical activity does not influence obesity risk: time to clarify the public health message. Int J Epidemiol. 2013;42(6):18311836 .

32. The Clinical Guidelines on the Identification, Evaluation, and Treatment of Overweight and Obesity in Adults: The Evidence Report. NIH Publication, USA: National Institutes of Health; 2018.

33. Rahmani-nia F, Daneshmandi H, Mehrabani J. The effects of a fitness program on endurance and fitness related knowledge in sedentary college males. Int J Fitness. 2007;3:33-40.

34. Saris WH, Blair SN, van Baak MA, et al. How much physical activity is enough to prevent unhealthy weight gain? Outcome of the IASO 1st Stock Conference and consensus statement. Obes Rev. 2003;4(2):101-114.

35. Baranowski T, Cullen KW, Nicklas T, et al. Are current health behavioral change models helpful in guiding prevention of weight gain efforts? Obes Res. 2003;11:23S-43.

36. Felson DT, Zhang Y, Anthony JM, et al. Weight loss reduces the risk for symptomatic knee osteoarthritis in women. Ann Intern Med. 1992;116(7):535-539.

37. Munnelly P, Feehan S. An obesity clinic model. Proceedings of the Nutrition Society. 2002;61(1):9-10.

38. Ali SM, Lindström M. Socioeconomic, psychosocial, behavioral, and psychological determinants of BMI among young women: differing patterns for underweight and overweight/obesity. Euro J Public Health. 2005;16(3):324-330.

39. Wareham NJ, van Sluijs EM, Ekelund U. Physical activity and obesity prevention: a review of the current evidence. Proc Nut Soc. 2005;64(2):229-247.

40. Wareham NJ. Physical activity and obesity prevention. Obesity rev. 2007;8(1):109-114.

41. Brown W, Bauman A, Chey T, et al. Comparison of surveys used to measure physical activity. Aust N Z J Public Health. 2004;28(2):128-134.

42. Erem C, Arslan C, Hacihasanoglu A, et al. Prevalence of obesity and association risk factors in Turkish population (Trabzon City, Turkey). Obes Res. 2004;12(7):1117-1127. 
43. Ogden CL, Carroll MD, McDowell MA, et al. Obesity among adults in the United States-no change since 2003-2004. NCHS Data Brief. 2007;(1):18

44. Kumanyika S, Jeffery RW, Morabia A, et al. Obesity prevention: the case for action. Int J Obes Relat Metab Disord. 2002;26(3):425-436.

45. Sturm R. The effects of obesity, smoking and drinking on medical problems and costs. Health Aff. 2002;21(2):245-253.

46. Brown DW, Balluz LS, Heath GW, et al. Association between recommended levels of physical activity and health-related quality of life/findings from the 2001 behavioral risk factor surveillance system (BRFSS) survey. Prev Med. 2003;37(5):520-528.

47. Byers T, Sedjo RL. Public health response to the obesity epidemic: too soon or too late? J Nutr. 2007;137(2):488-492.

48. Wolf AS. What is the economic case for treating obesity? Obes Res 1998;6(Suppl 1):2S-7.

49. Yanovski SZ, Yanovski JA. Obesity. N Engl J Med. 2002;346(8):591-602.

50. $\mathrm{Ng} \mathrm{M}$, Fleming $\mathrm{T}$, Robinson $\mathrm{M}$, et al. Global, regional and nationa prevalence of overweight and obesity in children and adults 1980-2013: A systematic analysis. Lancet. 2014;384(9945):766-s781.
51. A national profile of non-communicable disease risk factors in the Islamic Republic of Iran. Selected results of the first survey of the noncommunicable disease risk factor surveillance system of Iran, 2005-2006, Switzerland: WHO; 2005. p. 1-28.

52. Physical status: the use and interpretation of anthropometry. Report of a WHO Expert Committee. WHO technical report series No. 854 Switzerland: WHO; 1995.

53. Amoah AGB. Sociodemographic variations in obesity among Ghanaian adults. Pub Health Nutr. 2003;6(2003):751-757.

54. Worldwide trends in body-mass index, underweight, overweight, and obesity from 1975 to 2016 : a pooled analysis of 2416 population-based measurement studies in 128.9 million children, adolescents, and adults. Lancet. 2017;390:2627-2642.

55. Harnack LJ, Jeffery RW, Boutelle KN. Temporal trends in energy intake in the United States: an ecologic perspective. Am J Clin Nutr. 2000;71(6):1478-1484.

56. OECD/EU. Health at a Glance: Europe 2016: State of Health in the EU Cycle. Paris: OECD Publishing; 2016. 